\title{
Research on Control Strategy for Battery System of Photovoltaic Power System Based on Bi-directional DC/DC Converter
}

\author{
Li Xin, Xie Pu \\ (Department of Vehicle and Electrical Engineering, Ordnance Engineering College, \\ Shijiazhuang 050003, China)
}

Keywords: Independent photovoltaic system; battery energy management; bi-directional DC/DC

\begin{abstract}
Independent photovoltaic system needs energy storage in order to balance the power and improve its instability of power generation. A scientific control strategy can combine the PV cells to the battery system organically. The lithium-ion battery can be the bridge to achieve this target. This paper presents a control strategy which takes count of battery electrical performance and system instability based on optimization on the circuit topology of bi-directional DC/DC already underway. Moreover, the charge and discharge circuit based on bi-directional DC/DC converter and an integral independent PV power system are built with MATLAB, The simulation results show the correctness of the charge and discharge circuit topology and control strategy.
\end{abstract}

\section{Introduction}

Energy storage system with bi-directional DC-DC converter play a role in energy regulation of a stand-alone PV systems. Bi-directional DC-DC converter can make the DG system run between two quadrants and achieve two-way flow of energy, while maintaining the two ends of the DC voltage converter without changing the polarity. In recent years, with the promotion of photovoltaic technology, the research of DC-DC converter has become increasingly profound. A PWM small signal model is given in Ref. [1] where the battery using single current loop control, stabilize the output power fluctuations, but does not take into account the battery state of charge (SOC), in the practical realization, fail to guarantee the battery security system and stable . Ref. [2] proposed a model of independent photovoltaic power generation system structure, between high and low voltage isolation is achieved through two DC-DC converter. However, in the control strategy of battery, without considering the photovoltaic power generation of instability may bring to the bus voltage fluctuations.

Therefore, this paper puts forward a new energy storage system control strategy based on bidirectional DC-DC converter in the independent operation of photovoltaic power generation system, and the simulation model is verified.

\section{Overview of bidirectional DC-DC converter}

The battery plays a crucial role in independent photovoltaic power generation system, can supplement the shortage of supply of solar energy in light and storing extra solar energy. It is the only energy load in the case without illumination. Figure 1 shows the structure diagram of independent photovoltaic power generation system, through Bidirectional DC-DC converters achieve energy in the two-way flow of PV and battery, the power output can reach the requirement of the load.

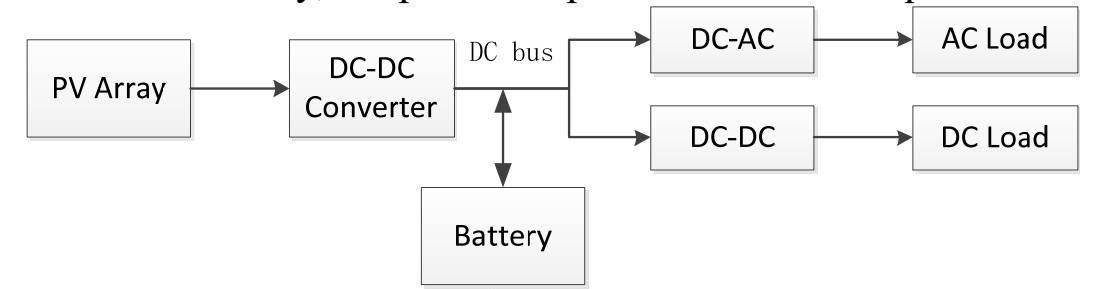

Fig. 1 Operation principle of independent photovoltaic system 
The commonly used bidirectional DC-DC mainly has the bidirectional lifting (Boost/Buck) and the transformer isolation type full bridge transformation and so on the main circuit topology structure form. Due to the large number of switches, the transformer isolation type is relatively low efficiency, which is generally used in large power systems. In the stand-alone photovoltaic system, the battery is connected to the low-voltage side, and does not need to be isolated. Therefore, the system uses a Boost/Buck converter, which will be the traditional Buck converter with the continuous flow of diodes into a two-way switching tube.

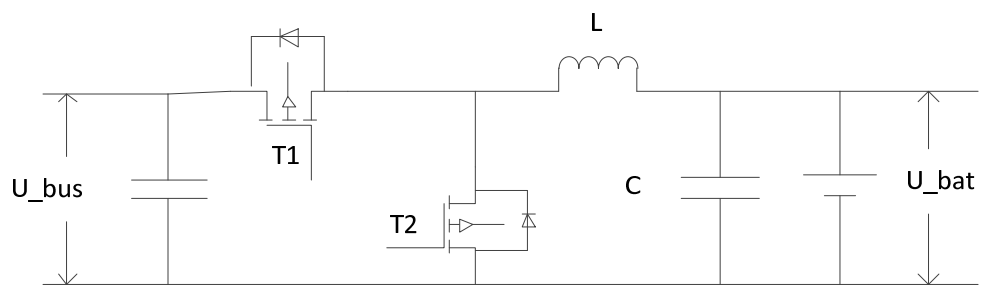

Fig. 2 Circuit topology of Boost/Buck converter

The topology of the Buck/Boost converter circuit is shown in Figure two. The circuit has 2 operating states:

1) When $T 2$ has been cut, the diode of switch tube T2 is used for freewheeling. At this time, DC / DC converter equivalent circuit for unidirectional buck converter, through the control of $\mathrm{T} 1$. Bidirectional converter control energy to the DC bus flow battery, the battery is charging status.

2) When T1 has been cut, the diode of switch tube T1 is used for freewheeling. At this time, DC / DC converter equivalent circuit for unidirectional boost converter, through the control of $\mathrm{T} 2$. Bidirectional converter control energy to the battery flow DC bus, the battery is discharging status.

\section{Battery charge and discharge control strategy}

As the battery charge and discharge time, speed and extent of the battery will have a serious impact on the electrical performance of the battery, charging efficiency and service life. The following principles must be followed when charging and discharging the battery: 1) as far as possible to avoid battery charging excessive or inadequate; 2) as far as possible to avoid the depth of discharge; 3 ) as far as possible to control the discharge current value. In this paper, the independent photovoltaic power generation system is based on the DC bus, the bus voltage level directly reflects the power supply capacity of the system. The control target of the bidirectional DC-DC converter is about to transform the wide range DC output voltage of the solar cell component to the DC bus voltage required by the load.

As shown in Figure 3, the control strategy is outlined as follows:

1) When the solar output power is greater than the load power, bi-directional converter working in Buck mode battery into charging state, the excess energy is stored. In battery state of charge (SOC) SOC $<80 \%$ constant flow charging mode, when the SOC is greater than or equal to $80 \%$ select a constant voltage charging mode, in consideration of the electrical performance of the battery and charging efficiency.

2) When the output of solar power is less than the load power, bi-directional converter working in boost mode battery into the discharge state, load the required energy compensation. Discharge mode selection constant pressure discharge, in order to maintain the balance of the bus voltage. 


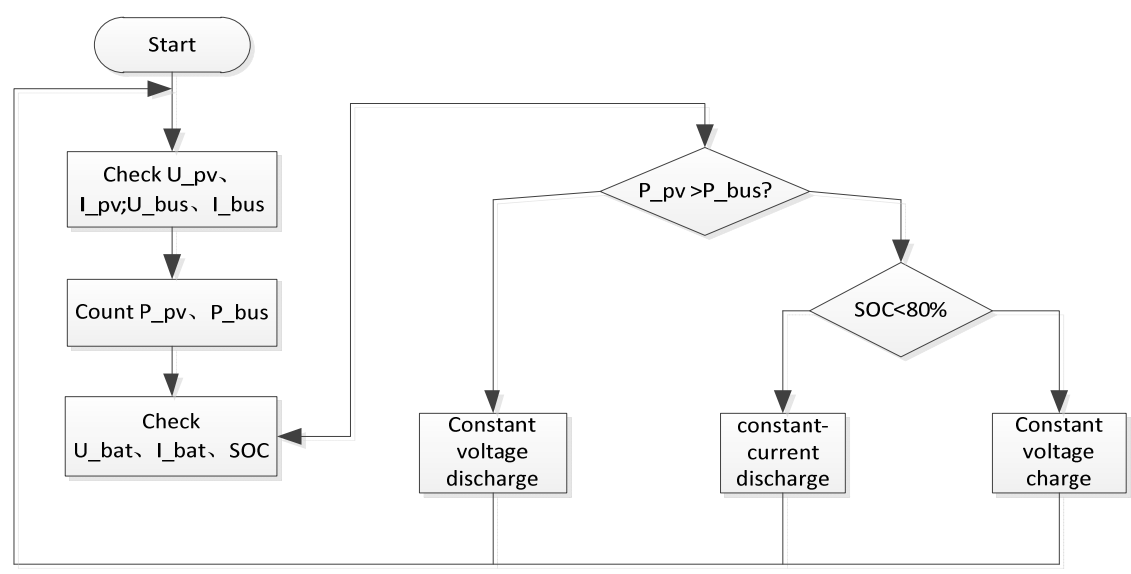

Fig. 3 Circuit topology of Boost/Buck converter

\section{Simulation experiment analysis}

According to the project needs, use MATLAB/Simulink to build a simulation model as shown in Figure 4. The PV module and battery module are both simplified model. Setting the normal operating range of the bus voltage is $380 \mathrm{~V} \sim 400 \mathrm{~V}$, the initial SOC of the battery is $40 \%$, and the rated voltage is $300 \mathrm{~V}$. System control module uses PI control. First of all, the difference between the load side power and the output power of the photovoltaic power generation is generated to control the operation mode of the DC-DC converter, which determines the working status of the battery. Then in the SOC of the battery voltage and current values and the reference values for the comparison of decision corresponding charging mode.

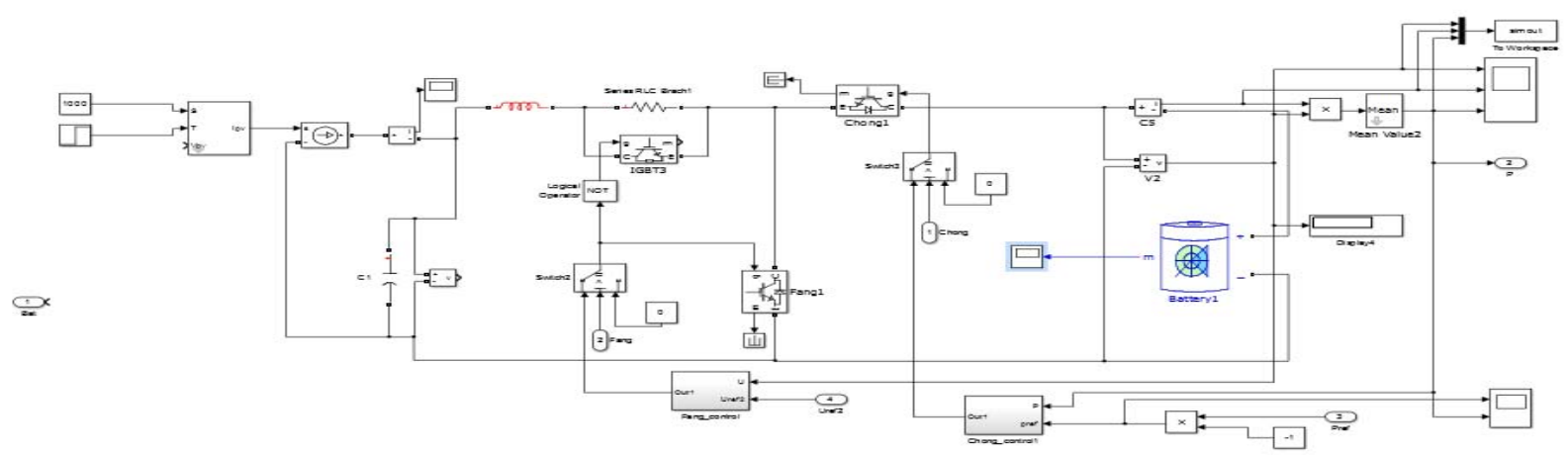

Fig. 4 Independent photovoltaic system energy storage link simulation model

As shown in Figure 5, the time a point for the $\mathrm{SOC}=80 \%$ time, the time $\mathrm{B}$ point for the SOC close to $100 \%$ times the battery voltage is $324 \mathrm{~V}$, Charge at $0 \sim$ a time with constant current $40 \mathrm{~A}$. Battery voltage gradually increased at a time SOC reached $80 \%$, at this time the battery voltage is $320 \mathrm{~V}$, conversion to constant voltage charging, charging voltage $330.4 \mathrm{~V}$, battery voltage continues to rise, the charge current drop. When the battery voltage reaches the $324 \mathrm{~V}$ charging current is weak, when the battery is in a near full state and then float, float voltage $325.2 \mathrm{~V}$. charging the whole process to ensure the battery quick charging at the same time, also can prevent overcurrent, rushed to the damage to the battery. Simulation results show that the correctness of the charging strategy. 


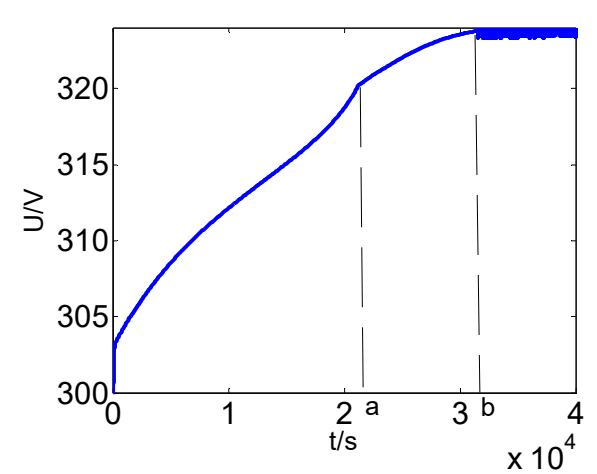

(a) Battery voltage

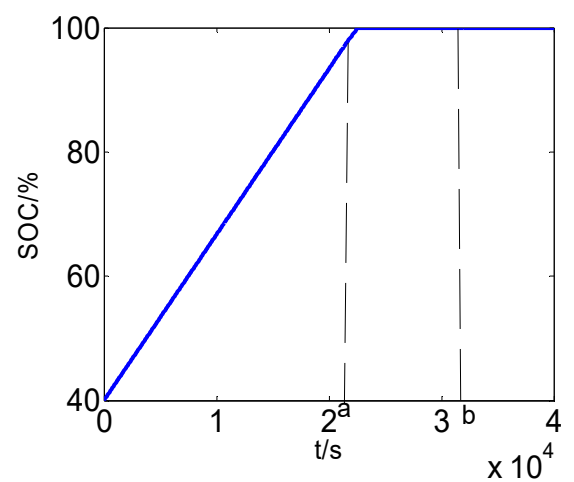

(c) battery SOC

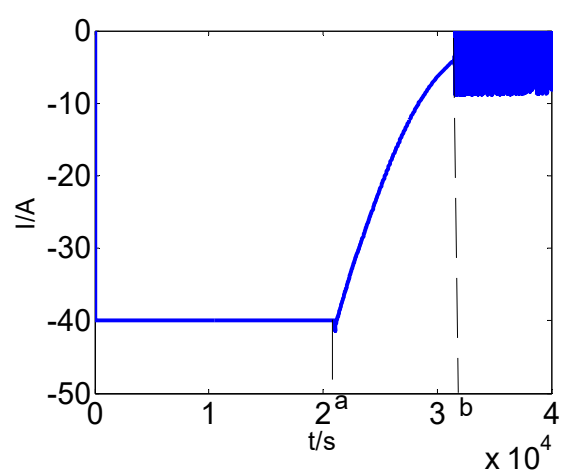

(b) battery charging current

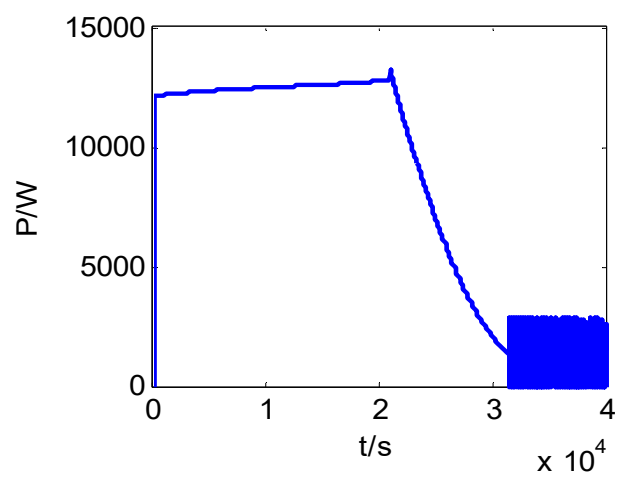

(d) battery charging power

Fig5. Simulation results of charging process

\section{Summary}

This paper for the stand-alone photovoltaic system commonly used bidirectional DC / DC converter structure, design a battery charge and discharge control strategy, in order to ensure the normal operation of the system based on, taking into account the protection of the electrical property of the battery and improve the charging speed dual goals. Through MATLAB / Simulink simulation of the control strategy is proved to be correct.

\section{Acknowledgement}

This paper is supported by National Natural Science Foundation of China (No.51307184)

\section{References}

[1] Yin Linlin, Study on PWM bidirectional DC/DC converter with soft switching, D. Guizhou University. (2008)

[2] Nandi S K, Ghosh H R. Prospect of wind-PV-battery hybrid power system as an alternative to grid extension in Bangladesh[J]. Energy, 2010, 35(7):3040-3047.

[3] Chen Y M, Huang A Q, Yu X. A High Step-Up Three-Port DC-DC Converter for Stand-Alone PV/Battery Power Systems[J]. IEEE Transactions on Power Electronics, 2013, 28(11):5049-5062.

[4] Barreto L H S C, Peixoto Praca P, Oliveira D S, et al. High-Voltage Gain Boost Converter Based on Three-State Commutation Cell for Battery Charging Using PV Panels in a Single Conversion Stage[J]. IEEE Transactions on Power Electronics, 2014, 29(1):150-158. 